\title{
Thrombotic and hemorrhagic events in 2016 World Health Organization-defined Philadelphia- negative myeloproliferative neoplasm
}

\author{
Ik-Chan Song ${ }^{1}$, Sang Hoon Yeon ${ }^{1}$, Myung-Won Lee ${ }^{1}$, Hyewon Ryu ${ }^{1}$, Hyo-Jin Lee ${ }^{1}$, Hwan-Jung Yun ${ }^{1}$, \\ Seon Young $\mathrm{Kim}^{2}$, and Deog-Yeon $\mathrm{Jo}^{1}$
}

${ }^{1}$ Division of Hematology/Oncology, Department of Internal Medicine, ${ }^{2}$ Department of Laboratory Medicine, Chungnam National University College of Medicine, Daejeon, Korea

Received: November 29, 2020 Revised : January 30, 2021 Accepted: February 5, 2021

\section{Correspondence to}

Deog-Yeon Jo, M.D.

Division of Hematology/

Oncology, Department of

Internal Medicine, Chungnam

National University Hospital, 282

Munhwa-ro, Jung-gu, Daejeon

35015, Korea

Tel: $+82-42-280-7162$

Fax: $+82-42-222-7141$

E-mail: deogyeon@cnu.ac.kr https://orcid.org/0000-0002-

8267-4214
Background/Aims: Recent changes in the diagnostic criteria for myeloproliferative neoplasms (MPNs) and increasing patient numbers necessitate updating of the data on vascular events in patients with such disorders.

Methods: In this single-center study, thrombotic and hemorrhagic events were retrospectively analyzed in patients diagnosed with essential thrombocythemia (ET), polycythemia vera (PV) prefibrotic/early primary myelofibrosis (pre-PMF), or PMF, based on the 2016 World Health Organization diagnostic criteria.

Results: Of a total of 335 consecutive patients (139 ET, 42 pre-PMF, 124 PV, and 30 PMF patients; 192 males and 143 females) of median age 64 years (range, 15 to 91), 112 (33.4\%) experienced a total of 126 thrombotic events before diagnosis, at the time of diagnosis, or during follow-up over a median of 4.6 years (range, 0.1 to 26.5). Cerebrovascular thrombosis (18.8\%) was the most common initial event, followed by coronary heart disease (10.1\%) and splanchnic (1.5\%) and peripheral thrombosis (1.5\%). Arterial thrombosis was more common than venous thrombosis (31.3\% vs. $2.1 \%$, respectively; $p=0.001$ ). Thrombosis was most frequent in PV patients (39.5\%), followed by patients with pre-PMF (38.1\%), ET (30.9\%), and PMF (13.3\%). Of the 112 patients who experienced thromboses, 53 (47\%) and 39 (33.9\%) had thrombotic events before and at the time of MPN diagnosis, respectively. Twenty-seven patients (8.1\%) experienced 29 hemorrhagic events, of which gastrointestinal bleeding $(n=20)$ was the most common.

Conclusions: Most thrombotic events occurred before or at the time of diagnosis, and the prevalence of arterial thrombosis was markedly higher than that of venous thrombosis in patients with MPN.

Keywords: Myeloproliferative neoplasm; Thrombocythemia, essential; Polycythemia vera; Thrombosis; Hemorrhage

\section{INTRODUCTION}

Thrombosis and hemorrhage are the main clinical manifestations of Philadelphia chromosome-negative myeloproliferative neoplasms (Ph- MPNs). It is well- known that arterial thrombosis is more common than venous thrombosis and that a significant proportion of thrombotic and hemorrhagic events occur before or at the time of MPN diagnosis [1]. The relevant reports have differed somewhat in terms of the percentages of throm- 
botic types and the timing of the events [2]. Apart from MPN, regional or ethnic differences in the incidence of thrombosis, including ischemic stroke and acute coronary syndrome (ACS), have been reported in general populations [3,4]. Thus, region- and race-specific data on thrombosis and hemorrhage in patients with MPNs are essential to manage these disorders more effectively. Although a few studies on thrombosis and hemorrhage in Korean MPN patients have appeared [5-7], the available information on vascular events is rather limited.

The diagnostic criteria for Ph- MPNs have been continuously revised [8-11]. Notably, the diagnostic thresholds of hemoglobin and hematocrit for polycythemia vera (PV) and that of platelet counts for essential thrombocythemia (ET) have been lowered considerably, and prefibrotic/early primary myelofibrosis (pre-PMF) has been defined more clearly in the diagnostic criteria proposed by the World Health Organization (WHO) [11]. Thus, some patients with early ET diagnoses are now classified as pre-PMF or PV patients [12-16], which necessitates the revision of early data on vascular events associated with MPNs. In addition, the number of newly diagnosed MPN patients is increasing in Korea [17-19], attributable, at least in part, to the changes in diagnostic criteria and widespread studies of driver gene mutations, strengthening the need to update the data on vascular events in patients with these disorders. In this retrospective study, we analyzed thrombotic and hemorrhagic events in a Korean population of patients with MPNs diagnosed on the basis of the 2016 WHO criteria.

\section{METHODS}

\section{Patients}

Patients who were diagnosed with ET, PV, pre-PMF, or primary myelofibrosis (PMF) from January 1996 to July 2020 at Chungnam National University Hospital were enrolled, and their medical records were reviewed. In patients diagnosed with ET prior to 2017, the diagnosis was revised based on the revised diagnostic criteria proposed by the WHO in 2016.

\section{Definitions of thrombotic and hemorrhagic events}

Thrombotic events included cerebrovascular (ischemic stroke, transient ischemic attack, and venous si- nus thrombosis), coronary (any ischemic heart disease, including ACS), splanchnic, and peripheral thromboembolism. Atherosclerosis obliterans was included in analysis. Hemorrhagic events were defined as any acute bleeding requiring red cell transfusion or admission. All events that occurred before, at the time of, and after diagnosis were included in the analysis.

\section{Statistical analysis}

Descriptive data are presented as mean \pm standard deviation, median (range), or percentages, and were compared using Student's $t$ test or the chi-square test (Fisher's exact test). To derive the cumulative probabilities of thrombosis and hemorrhage, and for survival analysis, Kaplan-Meier plots were drawn and analyzed using the log-rank test. Univariate and multivariate analyses of factors associated with the cumulative probabilities of thrombosis and hemorrhage were performed with the aid of Cox's proportional hazard analysis. Overall survival was defined as the time from MPN diagnosis to death from any cause. All statistical analyses were performed with SPSS software version 24.0 (IBM Co., Armonk, NY, USA), and $p<0.05$ was taken to indicate statistical significance.

\section{Ethics statement}

This study was approved by the Institutional Review Board of Chungnam National University Hospital (IRB No. CNUH 2020-01-027). The need for informed patient consent was waived given the retrospective nature of the analysis.

\section{RESULTS}

\section{Patient characteristics}

A total of 335 patients (139 ET, 42 pre-PMF, 124 PV, and 30 PMF; 192 male and 143 female) with a median age of 64 years (range, 15 to 91) were enrolled. They were followed up for a median of 4.6 years (range, 0.1 to 26.5). ET patients diagnosed before 2017 (designated as 'early ET' hereafter) were reviewed and their diagnoses revised based on the 2016 WHO diagnostic criteria. Of 129 'early ET' patients, 32 (24.8\%) and 11 (8.5\%) were re-classified as pre-PMF and PV patients, respectively. Palpable splenomegaly was most frequent in PMF (46.7\%), followed by 
Table 1. Patient characteristics

\begin{tabular}{|c|c|c|c|c|}
\hline Characteristic & $\operatorname{ET}(\mathrm{n}=139)$ & pre-PMF $(\mathrm{n}=42)$ & $\mathrm{PV}(\mathrm{n}=124)$ & $\operatorname{PMF}(\mathrm{n}=30)$ \\
\hline Age, yr & $64(15-88)$ & $63(22-88)$ & $64 \cdot 5(18-91)$ & $68.0(40-86)$ \\
\hline Female:Male & $69: 70$ & $19: 23$ & $45: 79$ & $10: 20$ \\
\hline Palpable splenomegaly & o & $2(4.8)$ & $9(7 \cdot 3)$ & $14(46.7)$ \\
\hline \multicolumn{5}{|l|}{ Laboratory findings } \\
\hline $\mathrm{WBC}, \times 10^{9} / \mathrm{L}$ & $11.1 \pm 4.5$ & $14.5 \pm 10.4^{\mathrm{a}}$ & $15 \cdot 3 \pm 7 \cdot 2$ & $13.4 \pm 11.0$ \\
\hline Monocytes, $\times 10^{9} / \mathrm{L}$ & $0.6 \pm 0.4$ & $0.8 \pm 0.4^{\mathrm{a}}$ & $0.7 \pm 0.4$ & $1.0 \pm 0.8$ \\
\hline Hemoglobin, g/dL & $13.6 \pm 2.2$ & $13.0 \pm 2.8$ & $18.2 \pm 2.7$ & $10.2 \pm 2.5$ \\
\hline Platelets, $\times 10^{9} / \mathrm{L}$ & $949.6 \pm 385.4$ & $1,000.9 \pm 746.0^{a}$ & $510.8 \pm 288.1$ & $414 \cdot 7 \pm 327.6$ \\
\hline $\mathrm{LDH}, \times \mathrm{UNL}$ & $1.1 \pm 0.5$ & $1.5 \pm 0.7^{\mathrm{a}}$ & $1.4 \pm 0.5$ & $2.1 \pm 1.6$ \\
\hline \multicolumn{5}{|l|}{ Driver gene mutation } \\
\hline JAK2V617F & $80 / 117(68.4)$ & $23 / 32(71.9)$ & $104 / 113(92.0)$ & $14 / 22(63.6)$ \\
\hline CALR & $14 / 117(12.0)$ & $4 / 32(12.5)$ & - & $5 / 22(22.7)$ \\
\hline$M P L$ & o/12 (0.0) & $0 / 3(0.0)$ & - & $0 / 3(0.0)$ \\
\hline JAK2 exon12 & - & - & $5 / 113(4.4)$ & - \\
\hline \multicolumn{5}{|l|}{ IPSET } \\
\hline Low & $43(30.9)$ & - & - & - \\
\hline Intermediate & $42(30.2)$ & - & - & - \\
\hline High & $54(38.8)$ & - & - & - \\
\hline \multicolumn{5}{|l|}{ IPSS } \\
\hline Low & - & $23(54.8)$ & - & $5(16.7)$ \\
\hline Intermediate-1 & - & $15(35 \cdot 7)$ & - & $8(26.7)$ \\
\hline Intemediate-2 & - & $3(7.1)$ & - & $11(36.7)$ \\
\hline High & - & $1(2.4)$ & - & $6(20.0)$ \\
\hline \multicolumn{5}{|l|}{ Comorbidity } \\
\hline Hypertension & $50(36.0)$ & $21(50.0)$ & $73(58.9)$ & $10(33 \cdot 3)$ \\
\hline Diabetes mellitus & $19(13.7)$ & $9(21.4)$ & $30(24.2)$ & $7(23 \cdot 3)$ \\
\hline Chronic kidney disease & $21(15.1)$ & $9(21.4)$ & $29(23.4)$ & $3(10.0)$ \\
\hline Smoking & $24(17 \cdot 3)$ & $12(28.6)$ & $50(40.3)$ & $3(10.0)$ \\
\hline \multicolumn{5}{|l|}{ Treatments } \\
\hline Cytoreductive treatment & $104(74.8)$ & $32(83 \cdot 3)$ & $107(86.3)$ & $16(53 \cdot 3)$ \\
\hline Aspirin & $134(96.4)$ & $38(90.1)$ & $116(93 \cdot 5)$ & $11(36.7)$ \\
\hline FU, mo & $46.1(0.3-289.3)$ & $58.1(0.4-269.5)$ & $76.6(0.3-317.9)$ & $40.2(0.8-236.8)$ \\
\hline
\end{tabular}

Values are presented as median (range), number (\%), or mean \pm SD.

ET, essential thrombocythemia; pre-PMF, prefibrotic/early primary myelofibrosis; PV, polycythemia vera; PMF, primary myelofibrosis; WBC, white blood cell; LDH, lactate dehydrogenase; UNL, upper normal limit; JAK2, Janus kinase 2; CALR, calreticulin; MPL, myeloproliferative leukemia; IPSET, International Prognostic Score in Essential Thrombocythemia; IPSS, International Prognostic Scoring System; FU, follow-up.

a $p=0.05$ compared with ET.

PV (7.3\%), and pre-PMF (4.8\%) patients. No ET patient exhibited palpable splenomegaly. The white blood cell, monocyte, and platelet counts, and the lactate dehy- drogenase level of pre-PMF patients, were higher than those of ET patients $\left(14.5 \pm 10.5 \times 10^{9} / \mathrm{L}\right.$ vs. $11.1 \pm 4.5 \times$ $10^{9} / \mathrm{L} ; 0.8 \pm 0.4 \times 10^{9} / \mathrm{L}$ vs. $0.6 \pm 0.4 \times 10^{9} / \mathrm{L} ; 1,000.9 \pm 746.0$ 
$\times 10^{9} / \mathrm{L}$ vs. $949.6 \pm 385.4 \times 10^{9} / \mathrm{L} ; 1.5 \pm 0.7 \times$ the upper normal limit [UNL] vs. $1.1 \pm 0.5 \times \mathrm{UNL}$, respectively; all $p<$ 0.05). The Janus kinase mutation (JAK2 $\left.\mathrm{V}_{17} \mathrm{~F}\right)$ mutation was most common in PV (92.0\%) patients, followed by pre-PMF (71.9\%), ET (68.4\%), and PMF (63.6\%) patients. The calreticulin (CALR) mutation was most frequent in PMF patients (22.7\%), followed by pre-PMF (12.5\%) and ET (12.0\%) patients. ET patients were evenly distributed among the International Prognostic Scoring in Essential Thrombocythemia (IPSET) risk groups. Most pre-PMF patients were in the low (54.8\%) or intermediate-1 $(35.7 \%)$ risk groups based on the International Prognostic Scoring System (IPSS); more PMF patients belonged to the intermediate-2 $(36.7 \%)$ or high (20.0\%) risk groups. Cytoreductive therapy was most commonly prescribed for PV patients (86.3\%), followed by pre-PMF (83.3\%), ET (74.8\%), and PMF (53.3\%) patients. Most patients were placed on low-dose aspirin across all MPN subtypes other than PMF (Table 1 ).

\section{Thrombotic events}

Of the 335 patients, 112 (33.4\%) experienced a total of 126 thrombotic events. Cerebrovascular thrombosis $(n=63$, 18.8\%) was the most common initial event, followed by coronary heart disease $(\mathrm{n}=34,10.1 \%)$ and splanchnic ( $\mathrm{n}$ $=5,1.5 \%)$ and peripheral thrombosis $(\mathrm{n}=5,1.5 \%)$. Arterial thrombosis was predominant compared to venous thrombosis ( $\mathrm{n}=105,31.3 \%$ vs. $\mathrm{n}=7,2.1 \%$, respectively; $p=0.001)$. Thrombotic events were most frequent in PV patients (39.5\%), followed by pre-PMF (38.1\%), ET (30.9\%), and PMF (13.3\%). Ischemic stroke was the most common initial event across MPN subtypes other than PMF (23.4\% in PV, $19.0 \%$ in pre-PMF, $12.9 \%$ in $\mathrm{ET}$, and $\circ \%$ in PMF). ACS was the next most common event $5.6 \%$ in $\mathrm{PV}, 2.4 \%$ in pre-PMF, $7.2 \%$ in $\mathrm{ET}$, and $6.7 \%$ in PMF). Deep vein thrombosis occurred in only two (0.6\%) patients (Table 2). Of the 112 patients who experienced thrombotic events, 53 (47\%) and 39 (33.9\%) experienced them before and at the time of MPN diagnosis, respectively; thus, only 21 (18.8\%) patients experienced thrombotic events after MPN diagnosis (Table 3). The cumulative probabilities of thrombosis for PV and pre-PMF patients tended to be higher than that for ET patients, but statistical significance was lacking (10-year probability $48 \%$ for PV and $48 \%$ for pre-PMF patients vs. $35 \%$ for ET patients, $p=0.358, p=0.433$; respectively).
The probability of thrombosis for PMF patients (10-year probability $13 \%)$ was lower than those for PV $(p=0.043)$ or pre-PMF $(p=0.046)$ patients (Fig. $1 \mathrm{~A})$. The cumulative probability of thrombosis for 'early ET' patients tended to be slightly higher than that for 2016 WHO-defined ET patients, but the difference was not statistically significant (10-year probability 40\% vs. 35\%, respectively; $p=$ 0.608 ) (Fig. 1B). The cumulative probability of thrombosis for pre-PMF patients in the IPSS intermediate-1 risk group was significantly higher than that for patients in the low-risk IPSS group (5-year probability 63\% vs. $23 \%$, respectively; $p=0.008$ ) (Fig. $1 \mathrm{C}$ ). With regard to thrombosis occurring after MPN diagnosis, the cumulative probability of thrombosis for PV patients tended to be higher than for other MPN subtypes, but the differences were not statistically significant (10-year probability = $20 \%$ for PV vs. $10 \%$ for ET vs. $3 \%$ for pre-PMF vs. $0 \%$ for PMF, $p=0.172)$ (Supplementary Fig. 1).

\section{Hemorrhagic events}

Of the 335 patients, 27 (8.1\%) experienced 29 hemorrhagic events. Gastrointestinal bleeding $(n=20,6.0 \%)$ was the most common initial event, followed by soft tissue bleeding $(\mathrm{n}=4,1.2 \%)$, central nervous system bleeding ( $\mathrm{n}$ $=2,0.6 \%)$, and genitourinary bleeding $(\mathrm{n}=1,0.3 \%$ ) (Table 2). Of the 27 patients, 12 (44.4\%) experienced hemorrhage after MPN diagnosis (Table 3). The cumulative probabilities of hemorrhage were similar among the MPN subtypes (Fig. 1D).

\section{Clinical features of MPN patients experiencing and not experiencing thrombotic events}

ET patients with thrombosis were older $(67.6 \pm 12.8$ years vs. $57.2 \pm 15.2$ years, respectively; $p=0.000)$, predominantly male $(66.7 \%$ vs. $43.3 \%$, respectively; $p=0.011)$, and exhibited higher positivity for JAK2 $\mathrm{V}_{11} \mathrm{~F}$ (81.3\% vs. 63.5\%, respectively; $p=0.045$ ) compared to those without (Table 4). No differences were observed in demographic features or laboratory findings between PV patients with and without thrombosis (Table 5). Pre-PMF patients with thromboses were older (69.1 \pm 9.2 years vs. $54.7 \pm 16.2$ years, respectively; $p=0.002$ ) and presented with lower platelet counts at diagnosis $\left(867.7 \pm 354.0 \times 10^{9} / \mathrm{L}\right.$ vs. 1,241 $\pm 483.0 \times 10^{9} / \mathrm{L}$, respectively; $\left.p=0.011\right)$ than those without thromboses (Table 6). PMF patients with thromboses were older $(77.3 \pm 3.3$ years vs. $63.1 \pm 12.6$ years, respective- 
Table 2. Thrombotic and hemorrhagic events

\begin{tabular}{|c|c|c|c|c|c|}
\hline Variable & $\mathrm{ET}(\mathrm{n}=139)$ & pre-PMF $(n=42)$ & $\mathrm{PV}(\mathrm{n}=124)$ & $\operatorname{PMF}(\mathrm{n}=30)$ & Total $(\mathrm{n}=335)$ \\
\hline \multicolumn{6}{|l|}{ Initial thrombotic event } \\
\hline \multicolumn{6}{|l|}{ Cerebrovascular } \\
\hline Stroke & $18(12.9)$ & $8(19.0)$ & $29(23.4)$ & 0 & $55(16.4)$ \\
\hline TIA & $4(2.9)$ & $2(4.8)$ & $1(0.8)$ & 0 & $7(2.1)$ \\
\hline VST & $1(0.7)$ & o & o & o & $1(0.3)$ \\
\hline Any & $23(16.5)$ & $10(23.8)$ & $30(24.2)$ & 0 & $63(18.8)$ \\
\hline \multicolumn{6}{|l|}{ Coronary } \\
\hline ACS & $10(7.2)$ & $1(2.4)$ & $7(5.6)$ & $2(6.7)$ & $20(6.0)$ \\
\hline Other & $5(3.6)$ & $3(7.1)$ & $4(3.2)$ & $2(6.7)$ & $14(4.2)$ \\
\hline Any & $15(10.8)$ & $4(9 \cdot 5)$ & $11(8.8)$ & $4(13 \cdot 4)$ & $34(10.1)$ \\
\hline \multicolumn{6}{|l|}{ Splanchnic } \\
\hline Arterial & $1(0.7)$ & 0 & 0 & 0 & $1(0.3)$ \\
\hline Venous & o & $1(2.4)$ & $3(2.4)$ & 0 & $4(1.2)$ \\
\hline Any & $1(0.7)$ & $1(2.4)$ & $3(2.4)$ & 0 & $5(1.5)$ \\
\hline \multicolumn{6}{|l|}{ Peripheral } \\
\hline Arterial & $1(0.7)$ & 0 & $2(1.6)$ & 0 & $3(0.9)$ \\
\hline Venous & 0 & $1(2.4)$ & $1(0.8)$ & 0 & $2(0.6)$ \\
\hline Any & $1(0.7)$ & $1(2.4)$ & $3(2.4)$ & 0 & $5(1.5)$ \\
\hline Atherosclerosis obliterans & $3(2.2)$ & o & $1(0.8)$ & 0 & $4(1.2)$ \\
\hline Total & $43(30.9)$ & $16(38.1)$ & $49(39.5)$ & $4(13 \cdot 3)$ & $112(33 \cdot 4)$ \\
\hline \multicolumn{6}{|c|}{ Vessels involved in initial thrombotic events } \\
\hline Arterial & $42(30.2)$ & $14(33 \cdot 3)$ & $45(36.3)$ & $4(13 \cdot 3)$ & $105(31.3)$ \\
\hline Venous & $1(0.7)$ & $2(4.8)$ & $4(3.2)$ & o & $7(2.1)$ \\
\hline Any & $43(30.9)$ & $16(38.1)$ & $49(39 \cdot 5)$ & $4(13 \cdot 3)$ & $112(33.4)$ \\
\hline \multicolumn{6}{|l|}{ Pooled thrombotic events } \\
\hline \multicolumn{6}{|l|}{ Cerebrovascular } \\
\hline Stroke & 21 & 8 & 35 & o & 64 \\
\hline TIA & 4 & 2 & 1 & 0 & 7 \\
\hline VST & 1 & o & o & $\mathrm{O}$ & 1 \\
\hline \multicolumn{6}{|l|}{ Coronary } \\
\hline ACS & 11 & 1 & 9 & 2 & 23 \\
\hline Others & 7 & 3 & 5 & 2 & 17 \\
\hline \multicolumn{6}{|l|}{ Splanchnic } \\
\hline Arterial & 1 & 0 & 0 & 0 & 1 \\
\hline Venous & o & 1 & 3 & o & 4 \\
\hline \multicolumn{6}{|l|}{ Peripheral } \\
\hline Arterial & $\mathrm{O}$ & 0 & 3 & 0 & 3 \\
\hline Venous & 0 & 1 & 1 & 0 & 2 \\
\hline Atherosclerosis obliterans & 3 & o & 1 & 0 & 4 \\
\hline Total & 48 & 16 & 58 & 4 & 126 \\
\hline \multicolumn{6}{|l|}{ Initial hemorrhagic event } \\
\hline CNS & $1(0.7)$ & o & $1(0.8)$ & o & $2(0.6)$ \\
\hline
\end{tabular}


Table 2. Continued

\begin{tabular}{|c|c|c|c|c|c|}
\hline Variable & $\operatorname{ET}(\mathrm{n}=139)$ & pre-PMF $(n=42)$ & $\mathrm{PV}(\mathrm{n}=124)$ & $\operatorname{PMF}(\mathrm{n}=30)$ & Total $(\mathrm{n}=335)$ \\
\hline Gastrointestinal & $6(4 \cdot 3)$ & $4(9.5)$ & $10(9.1)$ & o & $20(6.0)$ \\
\hline Genitourinary & $1(0.7)$ & 0 & 0 & 0 & $1(0.3)$ \\
\hline Soft tissue & $1(0.7)$ & o & $2(1.6)$ & $1(3 \cdot 3)$ & $4(1.2)$ \\
\hline Total & $9(6.5)$ & $4(9 \cdot 5)$ & $13(10.5)$ & $1(3 \cdot 3)$ & $27(8.1)$ \\
\hline \multicolumn{6}{|c|}{ Pooled hemorrhagic events } \\
\hline CNS & 1 & 0 & 2 & 0 & 3 \\
\hline Gastrointestinal & 6 & 4 & 11 & 0 & 21 \\
\hline Genitourinary & 1 & 0 & o & 0 & 1 \\
\hline Soft tissue & 1 & ० & 2 & 1 & 4 \\
\hline Total & 9 & 4 & 15 & 1 & 29 \\
\hline
\end{tabular}

Values are presented as number (\%).

ET, essential thrombocythemia; pre-PMF, prefibrotic/early primary myelofibrosis; PV, polycythemia vera; PMF, primary myelofibrosis; TIA, transient ischemic attack; VST, venous sinus thrombosis; ACS, acute coronary syndrome; CNS, central nervous system.

Table 3. Timing of thrombotic and hemorrhagic events

\begin{tabular}{|c|c|c|c|c|c|}
\hline Variable & $\operatorname{ET}(\mathrm{n}=139)$ & pre-PMF $(n=42)$ & $\mathrm{PV}(\mathrm{n}=124)$ & $\operatorname{PMF}(\mathrm{n}=30)$ & Total $(\mathrm{n}=335)$ \\
\hline \multicolumn{6}{|l|}{ Thrombotic events } \\
\hline Before diagnosis & $22(15.8)$ & $8(19.0)$ & $19(15 \cdot 3)$ & $4(13 \cdot 3)$ & $53(15.8)$ \\
\hline At diagnosis & $17(12.2)$ & $5(11.9)$ & $16(12.9)$ & $\mathrm{o}$ & $38(11.3)$ \\
\hline After diagnosis & $4(2.9)$ & $3(7.1)$ & $14(11.3)$ & o & $21(6.3)$ \\
\hline Total & $43(30.9)$ & $16(38.1)$ & $49(39 \cdot 5)$ & $4(13 \cdot 3)$ & $112(33.4)$ \\
\hline \multicolumn{6}{|l|}{ Hemorrhagic events } \\
\hline Before diagnosis & $4(2.9)$ & $2(4.8)$ & $4(3.2)$ & o & $10(3.0)$ \\
\hline At diagnosis & $1(0.7)$ & $2(4.8)$ & $2(1.6)$ & o & $5(1.5)$ \\
\hline After diagnosis & $4(2.9)$ & $0(0.0)$ & $7(5.6)$ & $1(3 \cdot 3)$ & $12(3.6)$ \\
\hline Total & $9(6.5)$ & $4(9 \cdot 5)$ & $13(10.5)$ & $1(3.3)$ & $27(8.1)$ \\
\hline
\end{tabular}

Values are presented as number (\%).

ET, essential thrombocythemia; pre-PMF, prefibrotic/early primary myelofibrosis; PV, polycythemia vera; PMF, primary myelofibrosis.

ly; $p=0.039)$ and exhibited less palpable splenomegaly (o\% vs. 53.8\%, respectively; $p=0.044$ ) than those without thromboses (Table 7).

\section{Risk factors for thrombosis and hemorrhage}

Cox's regression analysis of all MPN patients showed that age > 60 years (hazard ratio [HR], 1.88; 95\% confidence interval [CI], 1.09 to $3.02 ; p=0.022$ ), male sex (HR, 2.11; 95\% CI, 1.29 to 3.48; $p=0.003$ ), and hypertension (HR, 2.05; 95\% CI, 1.25 to $3.34 ; p=0.004$ ) were in- dependent risk factors for thrombosis (Table 8). In ET patients, other independent risk factors were chronic kidney disease (HR, 2.29; 95\% CI, 1.14 to $4.57 ; p=0.018$ ) and smoking (HR, 2.40; 95\% CI, 1.26 to $4.58 ; p=0.008$ ) (Supplementary Table 1); and, for pre-PMF patients, IPSS intermediate-1 risk versus low risk status (HR, 3.63; 95\% CI, 1.25 to $10.66 ; p=0.019$ ) (Supplementary Table 2 ). No other independent risk factors for thrombosis were found in PV patients (Supplementary Table 3). The results of Cox's regression analyses seeking risk factors 
A
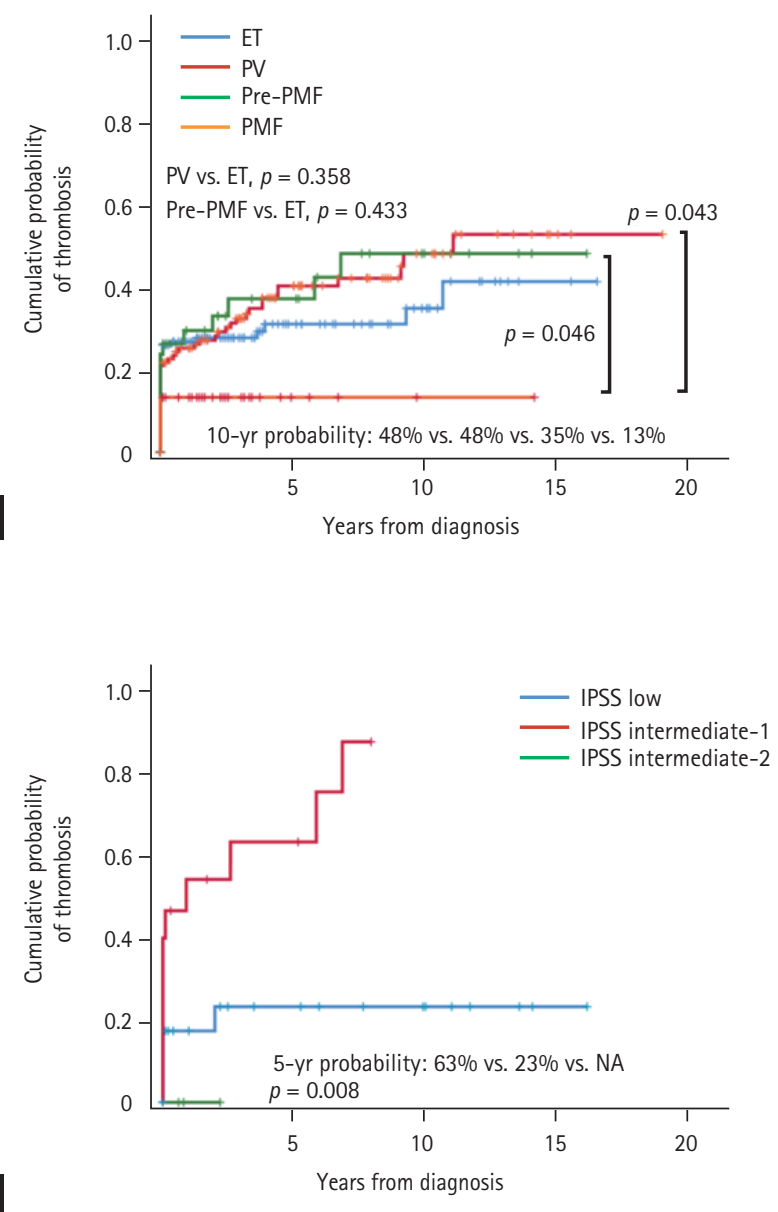
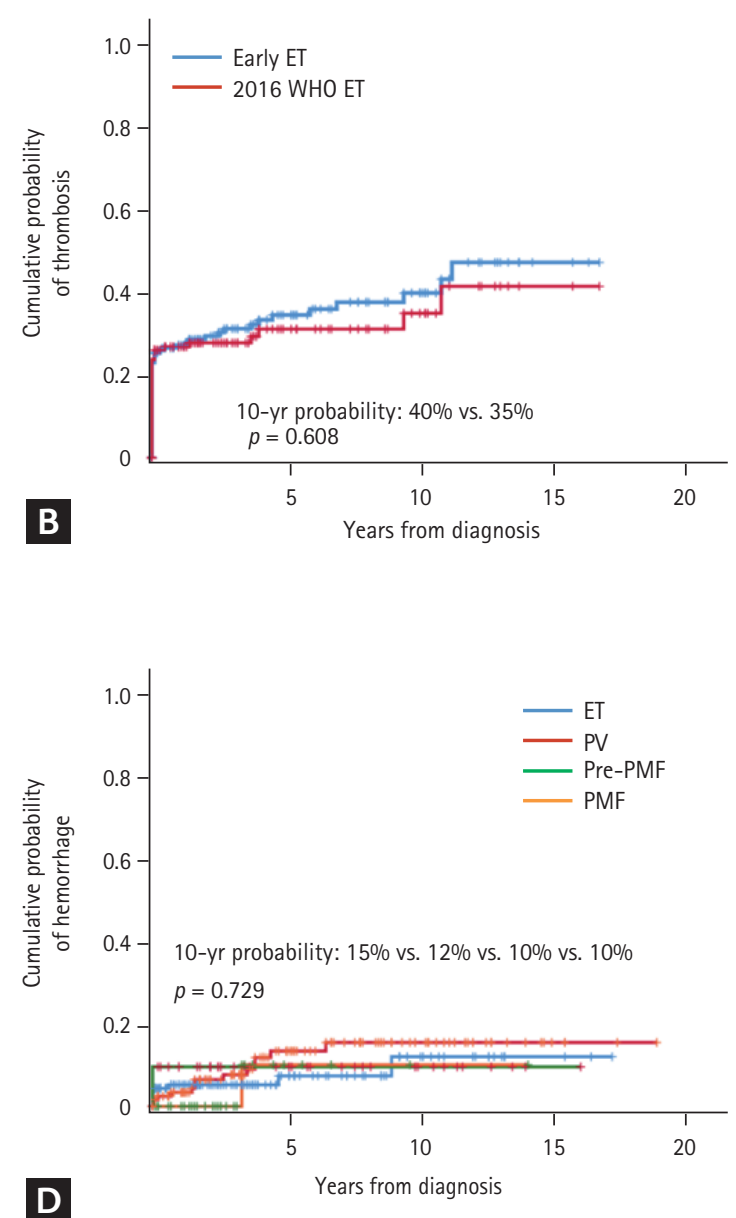

Figure 1. Cumulative probabilities of thrombosis and hemorrhage. (A) The probabilities of thrombosis in patients with the various myeloproliferative neoplasm (MPN) subtypes. (B) The probabilities of thrombosis in patients for whom essential thrombocythemia (ET) was diagnosed before 2016 ('Early ET') versus those whose diagnoses were revised based on the 2016 World Health Organization (WHO) diagnostic criteria ('2016 WHO ET'). (C) The probabilities of thrombosis in patients with prefibrotic/early primary myelofibrosis (pre-PMF) by their International Prognostic Scoring System (IPSS) risk scores. (D) The probabilities of hemorrhage in patients with the various MPN subtypes. PV, polycythemia vera; PMF, primary myelofibrosis; NA, not available.

for thrombosis occurring after MPN diagnosis $(\mathrm{n}=335)$ identified chronic kidney disease as the only independent risk factor (HR, 2.51; 95\% CI, 1.05 to $6.04 ; p=0.040$ ) (Supplementary Table 4). In the analysis of thrombosis occurring after ET diagnosis ( $\mathrm{n}=139)$, chronic kidney disease was again the only independent risk factor (HR, 9.02; 95\% CI, 1.86 to 43.84; $p=0.006$ ) (Supplementary Table 5). Male sex (HR, 4.57; 95\% CI, 1.32 to $9.68 ; p=0.012$ ) was the only risk factor for hemorrhage, as indicated by univariate analysis of all MPN patients (Supplementary Table 6).

\section{Overall survival}

Overall survival differed among the MPN subtypes, being fair for ET and PV, poor for pre-PMF, and worst for PMF patients (20-year survival: $79 \%$ of ET, $81 \%$ of PV, $63 \%$ of pre-PMF, and $55 \%$ of PMF patients, $p=0.005$ ) (Fig. 2). Thrombosis did not affect overall survival across the MPN subtypes; a modest tendency toward poorer overall survival was evident in ET, PV, and pre-PMF patients with than without thromboses (Supplementary Fig. 2). 
Table 4. Clinical features of essential thrombocythemia patients experiencing and not experiencing thrombotic events

\begin{tabular}{|c|c|c|c|}
\hline Variable & With TE $(n=42)$ & Without TE $(n=97)$ & $p$ value \\
\hline Age, yr & $67.6 \pm 12.8$ & $57.2 \pm 15.2$ & 0.000 \\
\hline Male sex & $28(66.7)$ & $42(43 \cdot 3)$ & 0.011 \\
\hline \multicolumn{4}{|l|}{ Laboratory findings } \\
\hline WBC, $\times 10^{9} / \mathrm{L}$ & $11.5 \pm 4.8$ & $10.9 \pm 4.4$ & 0.508 \\
\hline Monocytes, $\times 10^{9} / \mathrm{L}$ & $0.7 \pm 0.5$ & $0.6 \pm 0.3$ & 0.061 \\
\hline Hemoglobin, g/dL & $13.8 \pm 1.8$ & $12.5 \pm 2.3$ & 0.437 \\
\hline Platelets, $\times 10^{9} / \mathrm{L}$ & $979.0 \pm 387.9$ & $936.6 \pm 388.0$ & 0.555 \\
\hline $\mathrm{LDH}, \times \mathrm{UNL}$ & $1.1 \pm 0.3$ & $1.2 \pm 0.5$ & 0.667 \\
\hline \multicolumn{4}{|l|}{ Driver gene mutation } \\
\hline JAK2V6 ${ }_{17} \mathrm{~F}$ & $26 / 32(81.3)$ & $54 / 85(63.5)$ & 0.045 \\
\hline CALR & $2 / 32(6.3)$ & $12 / 85(14.1)$ & 0.058 \\
\hline IPSET & & & 0.000 \\
\hline Low & $1(2.4)$ & $42(43 \cdot 3)$ & \\
\hline Intermediate & $4(9.5)$ & $38(39.2)$ & \\
\hline High & $54(88.1)$ & $17(17.5)$ & \\
\hline R-IPSET-T & & & 0.000 \\
\hline Very low & $1(2.4)$ & $21(21.6)$ & \\
\hline Low & $0(0.0)$ & $25(25.8)$ & \\
\hline Intermediate & $1(2.4)$ & $7(7.2)$ & \\
\hline High & $36(85.7)$ & $33(34.0)$ & \\
\hline \multicolumn{4}{|l|}{ Comorbidity } \\
\hline Hypertension & $24(57.1)$ & $26(26.8)$ & 0.001 \\
\hline Diabetes mellitus & $5(11.9)$ & $14(14.4)$ & 0.690 \\
\hline Chronic kidney disease & $15(35 \cdot 7)$ & $6(6.2)$ & 0.000 \\
\hline Smoking & $14(33.3)$ & $10(10.3)$ & 0.001 \\
\hline Hemorrhagic event & $2(4.8)$ & $7(7.2)$ & 0.723 \\
\hline Follow-up duration, yr & $5.6 \pm 5.8$ & $6.2 \pm 5.9$ & 0.570 \\
\hline
\end{tabular}

Values are presented as mean \pm SD or number $(\%)$.

TE, thrombotic event; WBC, white blood cell; LDH, lactate dehydrogenase; UNL, upper normal limit; JAK2, Janus kinase 2; CALR, calreticulin; IPSET, International Prognostic Score in Essential Thrombocythemia; R-IPSET-T, revised IPSET-thrombosis score.

\section{DISCUSSION}

The prevalence, types, and times of occurrence of thrombosis (but not hemorrhage) that we report in the present study differ from those of previous studies in the West. A recent meta-analysis of 13,436 patients (49\% $\mathrm{ET}, 35 \% \mathrm{PV}$, and $14 \% \mathrm{MF}$ patients) reported pooled prevalence of (overall) thrombosis in 28.6\%, 20.7\%, and 9.5\% of patients newly diagnosed with PV, ET, and PMF, respectively [2]. The prevalence of thrombotic events that we report here is somewhat higher than reported previously. Geographic and/or ethnic differences may be in play. In addition, we broadened the definition of thrombotic events to include (especially) coronary vascular disease; this may have affected the prevalence. Many previous studies included only ACS (acute myocardial infarction and unstable angina) in the definitions of thrombotic coronary vascular disease; other ischemic heart diseases were excluded $[2,5,20]$. Recent studies have indicated that coronary microvascular function is 
Table 5. Clinical features of polycythemia vera patients experiencing and not experiencing thrombotic events

\begin{tabular}{|c|c|c|c|}
\hline Variable & With TE $(n=48)$ & Without TE $(n=76)$ & $p$ value \\
\hline Age, yr & $64.8 \pm 12.8$ & $60.4 \pm 14.8$ & 0.091 \\
\hline Male sex & $33(68.8)$ & $46(60.5)$ & 0.354 \\
\hline Palpable splenomegaly & $3(6.3)$ & $6(7 \cdot 9)$ & 0.731 \\
\hline \multicolumn{4}{|l|}{ Laboratory findings } \\
\hline WBC, $\times 10^{9} / \mathrm{L}$ & $15.8 \pm 8.5$ & $14.9 \pm 6.3$ & 0.492 \\
\hline Monocyte, $\times 10^{9} / \mathrm{L}$ & $0.8 \pm 0.5$ & $0.7 \pm 0.3$ & 0.124 \\
\hline Hemoglobin, g/dL & $17 \cdot 7 \pm 3.0$ & $18.4 \pm 2.3$ & 0.140 \\
\hline Platelet, $\times 10^{9} / \mathrm{L}$ & $544 \cdot 2 \pm 347 \cdot 3$ & $490.2 \pm 244.8$ & 0.325 \\
\hline $\mathrm{LDH}, \times \mathrm{UNL}$ & $1.4 \pm 0.6$ & $1.3 \pm 0.6$ & 0.849 \\
\hline \multicolumn{4}{|l|}{ Driver gene mutation } \\
\hline$J A K 2 V_{17} \mathrm{~F}$ & $36 / 39(92.3)$ & $59 / 67(88.1)$ & 0.449 \\
\hline JAK2 exon12 & $1 / 39(2.6)$ & $4 / 67(6.0)$ & 0.648 \\
\hline \multicolumn{4}{|l|}{ Comorbidity } \\
\hline Hypertension & $20(62.5)$ & $44(57 \cdot 9)$ & 0.611 \\
\hline Diabetes mellitus & $15(31.3)$ & $15(19.7)$ & 0.145 \\
\hline Chronic kidney disease & $10(20.8)$ & $21(27.6)$ & 0.394 \\
\hline Smoking & $21(43.8)$ & $29(38.2)$ & 0.536 \\
\hline Hemorrhagic event & $7(14.6)$ & $6(7 \cdot 9)$ & 0.236 \\
\hline Follow-up duration, yr & $7 \cdot 2 \pm 5 \cdot 7$ & $8.2 \pm 6.5$ & 0.344 \\
\hline
\end{tabular}

Values are presented as mean $\pm \mathrm{SD}$ or number (\%).

TE, thrombotic events; WBC, white blood cell; LDH, lactate dehydrogenase; UNL, upper normal limit; JAK2, Janus kinase 2.

impaired even in MPN patients lacking ischemic heart disease [21] and that driver gene mutations, especially JAK2 V6 $17 F$, induce vascular endothelial cell dysfunction [22-24] and may contribute to the development of atherosclerosis. Therefore, it seems reasonable to define all ischemic heart diseases, unless they are associated with underlying heart disorders, as thrombotic coronary vascular events. This is what we did, possibly contributing (at least in part) to the higher prevalence of thrombotic events.

Most previous studies focused principally on vascular events occurring after MPN diagnosis, which may have given rise to erroneous, overall pooled prevalence and lifetime risks of MPN-associated events. We included all thrombotic events occurring soon before, at the time of, and after diagnosis of MPN, which may contribute to the higher prevalence of events that we report. Most previous studies found that about one-third (up to two-thirds in a few studies) of all thrombotic events occurred before or at the time of MPN diagnosis [1,2,20]; most studies were performed in the West. In one study reporting that $38.1 \%$ of 239 Korean ET patients experienced thrombohemorrhagic events, $64.8 \%$ of the events occurred before or at the time of MPN diagnosis [6]. In another study reporting that $33.4 \%$ of 102 Korean MPN patients (69 with ET and 33 with PV) experienced coronary vascular or cerebrovascular, arterial thrombotic events; $51.5 \%$ of all events occurred before or at the time of MPN diagnosis. Unlike previous reports, we found that $81 \%$ of initial thrombotic events occurred soon before MPN diagnosis or at the time of diagnosis. These results highlight the importance of early MPN detection, in addition to appropriate management after diagnosis. The results may have been at least partly due to our hospital running a Regional Cardio-Cerebrovascular Center designated by the Korean Ministry of Health and Welfare for the past 10 years, such that recruited more patients with vascular events to this study. 
Table 6. Clinical features of prefibrotic/early primary myelofibrosis patients experiencing and not experiencing thrombotic events

\begin{tabular}{|c|c|c|c|}
\hline Variable & With TE $(n=16)$ & Without TE $(n=26)$ & $p$ value \\
\hline Age, yr & $69.1 \pm 9.2$ & $54 \cdot 7 \pm 16.2$ & 0.002 \\
\hline Male sex & $10(62.5)$ & $13(50.0)$ & 0.429 \\
\hline Palpable splenomegaly & $1(6.3)$ & $1(3.8)$ & 0.722 \\
\hline \multicolumn{4}{|l|}{ Laboratory findings } \\
\hline $\mathrm{WBC}, \times 10^{9} / \mathrm{L}$ & $11.4 \pm 5.1$ & $16.3 \pm 12.3$ & 0.140 \\
\hline Monocytes, $\times 10^{9} / \mathrm{L}$ & $0.9 \pm 0.5$ & $0.7 \pm 0.5$ & 0.130 \\
\hline Hemoglobin, g/dL & $13.8 \pm 1.3$ & $12.5 \pm 3.4$ & 0.137 \\
\hline Platelets, $\times 10^{9} / \mathrm{L}$ & $867.7 \pm 354.0$ & $1,241.1 \pm 483.0$ & 0.011 \\
\hline $\mathrm{LDH}, \times \mathrm{UNL}$ & $1.7 \pm 0.9$ & $1.4 \pm 0.4$ & 0.243 \\
\hline \multicolumn{4}{|l|}{ Driver gene mutation } \\
\hline$J A K 2 V_{17} \mathrm{~F}$ & $9 / 12(75.0)$ & $14 / 21(66.7)$ & 0.802 \\
\hline CALR & $1 / 12(8.3)$ & $2 / 21(9.5)$ & 0.355 \\
\hline IPSS & & & 0.005 \\
\hline Low & $5(31.3)$ & $18(69.2)$ & \\
\hline Intermediate-1 & $11(68.8)$ & $4(15 \cdot 4)$ & \\
\hline Intermediate-2 & 0 & $3(11.5)$ & \\
\hline High & $\mathrm{O}$ & $1(3.8)$ & \\
\hline \multicolumn{4}{|l|}{ Comorbidity } \\
\hline Hypertension & $8(50.0)$ & $13(50.0)$ & 1.000 \\
\hline Diabetes mellitus & $4(25 \cdot 0)$ & $5(19.2)$ & 0.658 \\
\hline Chronic kidney disease & $4(25 \cdot 0)$ & $5(19.2)$ & 0.658 \\
\hline Smoking & $5(31.3)$ & $7(26.9)$ & 0.763 \\
\hline Hemorrhagic event & $\mathrm{O}$ & $4(15 \cdot 4)$ & 0.099 \\
\hline Follow-up duration, yr & $7.0 \pm 5.4$ & $7.2 \pm 7.1$ & 0.956 \\
\hline
\end{tabular}

Values are presented as mean $\pm \mathrm{SD}$ or number $(\%)$.

TE, thrombotic events; WBC, white blood cell; LDH, lactate dehydrogenase; UNL, upper normal limit; JAK2, Janus kinase 2; IPSS, International Prognostic Scoring System.

Current models seeking to predict thrombosis in ET patients were established by analyzing patient populations in whom large numbers of thrombotic events occurred after MPN diagnosis [25-27]. In the revised IPSET-thrombosis model, the risk factors for thrombosis are older age, JAK2 $\mathrm{VG}_{17} \mathrm{~F}$-positivity, and a history of thrombosis [27]. About two-thirds of all thromboses occurred after MPN diagnosis in the patient population analyzed when constructing this model, unlike what we found. However, older age was indeed independently predictive of thrombosis in all MPN patients. In patients with ET, those who developed thromboses were some- what older and more often JAK2V61jF-positive than others, but Cox's regression analysis did not indicate that older age or JAK2V61jF-positivity were independent risk factors for thrombosis. This may be because most thrombotic events of the present study occurred before or at the time of diagnosis. A history of thrombosis was shown not to predict future thrombosis in all patients with MPNs, nor in patients with ET. Similarly, neither older age nor JAK2 $\mathrm{VG}_{17} \mathrm{~F}$ positivity predicted thrombosis after diagnosis. These results may have been due to the relatively small number of patients and short follow-up duration in a large proportion thereof. Therefore, fur- 
Table 7. Clinical features of primary myelofibrosis patients experiencing and not experiencing thrombotic events

\begin{tabular}{|c|c|c|c|}
\hline Variable & With TE $(n=4)$ & Without TE $(n=26)$ & $p$ value \\
\hline Age, yr & $77.0 \pm 3 \cdot 3$ & $63.1 \pm 12.6$ & 0.039 \\
\hline Male sex & $3(75 \cdot 0)$ & $17(65 \cdot 4)$ & 0.704 \\
\hline Palpable splenomegaly & $\mathrm{O}$ & $14(53.8)$ & 0.044 \\
\hline \multicolumn{4}{|l|}{ Laboratory findings } \\
\hline $\mathrm{WBC}, \times 10^{9} / \mathrm{L}$ & $10.8 \pm 6.0$ & $13.8 \pm 11.6$ & 0.626 \\
\hline Monocytes, $\times 10^{9} / \mathrm{L}$ & $1.2 \pm 1.3$ & $0.9 \pm 0.7$ & 0.513 \\
\hline Hemoglobin, g/dL & $10.0 \pm 1.4$ & $10.3 \pm 2.7$ & 0.831 \\
\hline Platelets, $\times 10^{9} / \mathrm{L}$ & $784.8 \pm 565.8$ & $357 \cdot 5 \pm 246.4$ & 0.012 \\
\hline $\mathrm{LDH}, \times \mathrm{UNL}$ & $1.5 \pm 0.2$ & $2.2 \pm 1.7$ & 0.463 \\
\hline \multicolumn{4}{|l|}{ Driver gene mutation } \\
\hline JAK2V617F & $3 / 4(75.0)$ & $11 / 18(61.1)$ & 0.362 \\
\hline CALR & $0 / 4(0.0)$ & $5 / 18(27.8)$ & 0.562 \\
\hline IPSS & & & 0.543 \\
\hline Low & 0 & $5(19.2)$ & \\
\hline Intermediate-1 & $2(50.0)$ & $6(23.1)$ & \\
\hline Intermediate-2 & $2(50.0)$ & $9(34.6)$ & \\
\hline High & 0 & $6(23.1)$ & \\
\hline \multicolumn{4}{|l|}{ Comorbidity } \\
\hline Hypertension & $3(75.0)$ & $7(26.9)$ & 0.058 \\
\hline Diabetes mellitus & $1(25.0)$ & $6(23.1)$ & 0.933 \\
\hline Chronic kidney disease & 0 & $3(11.5)$ & 0.474 \\
\hline Smoking & $\mathrm{O}$ & $3(11.5)$ & 0.474 \\
\hline Hemorrhagic event & $\mathrm{O}$ & $1(3.8)$ & 0.867 \\
\hline Follow-up duration, yr & $2.4 \pm 2.2$ & $4 \cdot 5 \pm 4 \cdot 4$ & 0.365 \\
\hline
\end{tabular}

Values are presented as mean $\pm \mathrm{SD}$ or number $(\%)$.

TE, thrombotic event; WBC, white blood cell; LDH, lactate dehydrogenase; UNL, upper normal limit; JAK2, Janus kinase 2; CALR, calreticulin; IPSS, International Prognostic Scoring System.

ther studies are warranted.

Many studies have found that thromboses were more common in PV than ET patients [1,2,20]. In the present study, we observed a similar trend (PV vs. ET; $39.5 \%$ vs. 30.9\%); however, statistical significance was not attained. In 2016, the WHO revised the classification of MPNs, and pre-PMF became recognized as a separate entity (distinct from ET). Over the past few years, several studies have re-evaluated the clinical features of ET and pre-PMF, because most pre-PMF patients were previously diagnosed with ET. A critical review of such works found that pre-PMF usually exhibits distinct clinical and hematological presentations, and a higher (compared to ET) frequency of constitutional symptoms, but the thrombosis incidence does not differ significantly from that of ET patients [28]. We found that somewhat more pre-PMF than ET patients experienced thromboses (38.1\% vs. $30.9 \%$, respectively) but, again, the difference was not statistically significant, consistent with recent observations. Thrombosis was significantly more frequent in pre-PMF patients in the IPSS intermediate-1 risk group than the low risk group; active prevention is required in such patients.

It is well known that arterial thrombosis is more common than venous thrombosis in MPN patients. The meta-analysis cited above indicated that arterial thrombosis (pooled prevalence 16.2\%: cerebrovascular 7.4\%, transient ischemic attack $3.5 \%$, and coronary heart dis- 
Table 8. Cox's regression analysis seeking risk factors for thrombosis in patients with myeloproliferative neoplasms $(\mathrm{n}=335)$

\begin{tabular}{|c|c|c|c|c|c|c|}
\hline \multirow{2}{*}{ Variable } & \multicolumn{3}{|c|}{ Univariate analysis } & \multicolumn{3}{|c|}{ Multivariate analysis } \\
\hline & $\mathrm{HR}$ & $95 \% \mathrm{CI}$ & $p$ value & $\mathrm{HR}$ & $95 \% \mathrm{CI}$ & $p$ value \\
\hline Age $>60$ years & 1.76 & $1.16-2.66$ & 0.008 & 1.62 & $1.06-2.49$ & 0.027 \\
\hline Male sex & 1.25 & $1.02-1.53$ & 0.031 & 1.67 & $1.11-2.52$ & 0.014 \\
\hline Palpable splenomegaly & 0.48 & $0.18-1.30$ & 0.146 & - & - & - \\
\hline $\mathrm{WBC}>12.0 \times 10^{9} / \mathrm{L}$ & 1.28 & $0.87-1.89$ & 0.207 & - & - & - \\
\hline Platelets > 1,000 × $10^{9} / \mathrm{L}$ & 0.94 & $0.60-1.49$ & 0.794 & - & - & - \\
\hline $\mathrm{LDH}>1.5 \times \mathrm{UNL}$ & 0.82 & $0.50-1.35$ & 0.441 & - & - & - \\
\hline Positive for $\mathrm{JAK}_{2} \mathrm{~V} \mathrm{G}_{17} \mathrm{~F}$ & 1.94 & $1.05-3.58$ & 0.035 & 1.23 & $0.77-1.98$ & 0.199 \\
\hline ET & 0.91 & $0.61-1.35$ & 0.634 & - & - & - \\
\hline Pre-PMF & 1.37 & $0.75-2.16$ & 0.681 & - & - & - \\
\hline PV & 1.24 & $0.84-1.83$ & 0.274 & - & - & - \\
\hline Hypertension & 1.71 & $1.16-2.52$ & 0.007 & 1.59 & $1.06-2.36$ & 0.024 \\
\hline Diabetes mellitus & 1.36 & $0.86-2.17$ & 0.193 & - & - & - \\
\hline Chronic kidney disease & 1.50 & $0.96-2.34$ & 0.072 & 1.11 & $0.70-1.78$ & 0.659 \\
\hline Smoking & 1.66 & $1.11-2.48$ & 0.013 & 1.36 & $0.87-2.13$ & 0.181 \\
\hline
\end{tabular}

HR, hazard ratio; CI, confidence interval; WBC, white blood cell; LDH, lactate dehydrogenase; UNL, upper normal limit; JAK2, Janus kinase 2; ET, essential thrombocythemia; pre-PMF, prefibrotic/early primary myelofibrosis; PV, polycythemia vera.

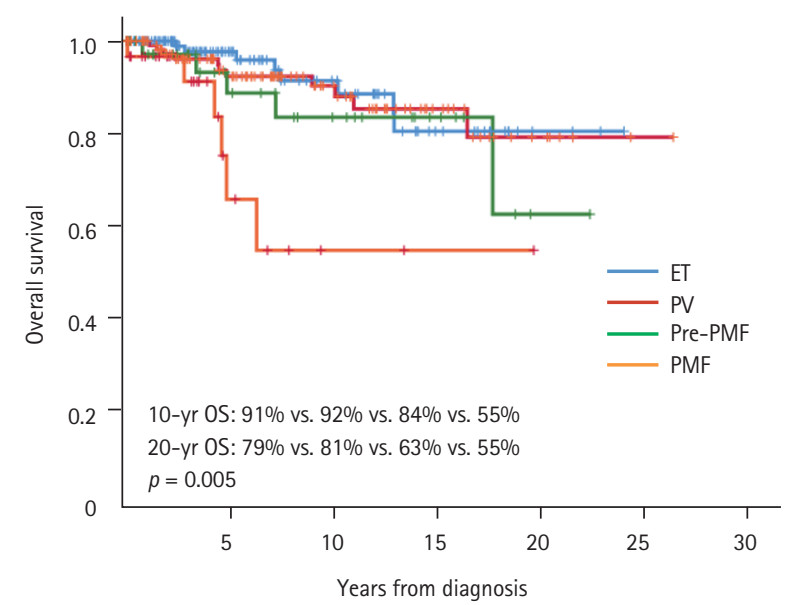

Figure 2. Overall survival (OS) of patients with the various myeloproliferative neoplasm subtypes. ET, essential thrombocythemia; PV, polycythemia vera; pre-PMF, prefibrotic/ early primary myelofibrosis; PMF, primary myelofibrosis.

ease $6.1 \%$ ) was more common than venous thrombosis (pooled prevalence 6.2\%: deep vein thrombosis 3.4\%, splanchnic vein thrombosis 1.4\%, pulmonary embolism $0.9 \%$, and cerebral venous thrombosis $0.7 \%$ ) [2]. A German prospective study of 454 MPN patients reported that $33.6 \%$ experienced thromboses; deep vein thrombo- sis was most common (10.1\%), followed by ACS (9.0\%), and ischemic stroke (6.2\%) [20]. Arterial thrombosis had a far higher prevalence in our study than reported in the cited work (31.3\% vs. $2.1 \%$, respectively). Notably, ischemic stroke was more common than coronary vascular events, and deep vein thrombosis was rare, quite unlike Western studies but similar to a previous study in Korean ET patients [6]. Geographic or ethnic differences may be in play, given that ischemic stroke is more prevalent in Korea than in the West [3]. Interestingly, four of our patients (three ET patients and one PV patient) presented with atherosclerosis obliterans. The possible association of this condition with MPN has not been explored, and any etiological relationship remains unclear. Given the recent evidence that MPN affects vascular endothelial cells and triggers atherosclerosis [22-24], we included the condition in the pool of thrombotic vascular events.

Unlike our findings regarding thrombotic events, the incidence and pattern of hemorrhagic events were similar to those described in previous reports. In the abovementioned meta-analysis, the pooled prevalence of bleeding was $6.2 \%$. The MPN subtype affected the bleeding risk, which was highest in MF patients (8.9\%), followed by ET (7.3\%) and PV (6.9\%) patients. Bleeding 
was mucocutaneous, gastrointestinal, epitaxic, and postoperative $[2,20,29]$.

As expected, the overall survival of pre-PMF patients was significantly poorer than those of ET and PV patients. The overall survival of PMF patients was significantly poorer than those of patients with other MPNs. ET, PV, and pre-PMF patients with thromboses tended to exhibit poorer overall survival than those without thromboses, but statistical significance was not attained. Future studies with larger numbers of patients are required.

In summary, the pattern of thrombotic vascular events in our study cohort differed from that in Western countries in certain respects. Arterial thrombosis was far more prevalent than venous thrombosis, ischemic stroke was more common, and deep vein thrombosis was much rarer. Notably, most thrombotic events occurred before or at the time of MPN diagnosis, highlighting the importance of early MPN detection.

\section{KEY MESSAGE}

1. Arterial thrombosis was far more prevalent than venous thrombosis, whereas deep vein thrombosis was far less prevalent, than in the West.

2. The cumulative probability of thrombosis in patients with prefibrotic/early primary myelofibrosis was similar to that in patients with essential thrombocythemia.

3. Most thrombotic events occurred before or at the time of myeloproliferative neoplasm (MPN) diagnosis, highlighting the importance of early MPN detection.

\section{Conflict of interest}

No potential conflict of interest relevant to this article was reported.

\section{Acknowledgments}

This study was financially supported by Research Fund of Chungnam National University Hospital.

\section{REFERENCES}

1. Stein BL, Martin K. From Budd-Chiari syndrome to acquired von Willebrand syndrome: thrombosis and bleeding complications in the myeloproliferative neoplasms. Hematology Am Soc Hematol Educ Program 2019;2019:397-406.

2. Rungjirajittranon T, Owattanapanich W, Ungprasert P, Siritanaratkul N, Ruchutrakool T. A systematic review and meta-analysis of the prevalence of thrombosis and bleeding at diagnosis of Philadelphia-negative myeloproliferative neoplasms. BMC Cancer 2019;19:184.

3. GBD 2016 Lifetime Risk of Stroke Collaborators, Feigin VL, Nguyen G, et al. Global, regional, and country-specific lifetime risks of stroke, 1990 and 2016. N Engl J Med 2018;379:2429-2437.

4. Andre R, Bongard V, Elosua R, et al. International differences in acute coronary syndrome patients' baseline characteristics, clinical management and outcomes in Western Europe: the EURHOBOP study. Heart 2014;100:12011207.

5. Bang SM, Lee JS, Ahn JY, et al. Vascular events in Korean patients with myeloproliferative neoplasms and their relationship to JAK2 mutation. Thromb Haemost 2009;101:547-551.

6. Lee HS, Park LC, Lee EM, et al. Incidence rates and risk factors for vascular events in patients with essential thrombocythemia: a multicenter study from Korea. Clin Lymphoma Myeloma Leuk 2012;12:70-75.

7. Lim Y, Lee JO, Kim SH, et al. Prediction of thrombotic and hemorrhagic events during polycythemia vera or essential thrombocythemia based on leukocyte burden. Thromb Res 2015;135:846-851.

8. Wasserman LR. Polycythemia vera study group: a historical perspective. Semin Hematol 1986;23:183-187.

9. Michiels JJ, Juvonen E. Proposal for revised diagnostic criteria of essential thrombocythemia and polycythemia vera by the Thrombocythemia Vera Study Group. Semin Thromb Hemost 1997;23:339-347.

10. Vardiman JW, Thiele J, Arber DA, et al. The 2008 revision of the World Health Organization (WHO) classification of myeloid neoplasms and acute leukemia: rationale and important changes. Blood 2009;114:937-951.

11. Arber DA, Orazi A, Hasserjian R, et al. The 2016 revision to the World Health Organization classification of myeloid neoplasms and acute leukemia. Blood 2016;127:2391- 
2405 .

12. Jeryczynski G, Thiele J, Gisslinger B, et al. Pre-fibrotic/ early primary myelofibrosis vs. WHO-defined essential thrombocythemia: the impact of minor clinical diagnostic criteria on the outcome of the disease. Am J Hematol 2017;92:885-891.

13. Gisslinger H, Jeryczynski G, Gisslinger B, et al. Clinical impact of bone marrow morphology for the diagnosis of essential thrombocythemia: comparison between the BCSH and the WHO criteria. Leukemia 2016;30:1126-1132.

14. Kamiunten A, Shide K, Kameda T, et al. Early/prefibrotic primary myelofibrosis in patients who were initially diagnosed with essential thrombocythemia. Int J Hematol 2018;108:411-415.

15. Barbui T, Thiele J, Gisslinger H, Carobbio A, Vannucchi AM, Tefferi A. Diagnostic impact of the 2016 revised who criteria for polycythemia vera. Am J Hematol 2017;92:417419.

16. Edahiro Y, Araki M, Inano T, et al. Clinical and molecular features of patients with prefibrotic primary myelofibrosis previously diagnosed as having essential thrombocythemia in Japan. Eur J Haematol 2019;102:516-520.

17. Choi CW, Bang SM, Jang S, et al. Guidelines for the management of myeloproliferative neoplasms. Korean J Intern Med 2015;30:771-788.

18. Lim Y, Lee JO, Bang SM. Incidence, survival and prevalence statistics of classical myeloproliferative neoplasm in Korea. J Korean Med Sci 2016;31:1579-1585.

19. Byun JM, Kim YJ, Youk T, Yang JJ, Yoo J, Park TS. Real world epidemiology of myeloproliferative neoplasms: a population based study in Korea 2004-2013. Ann Hematol 2017;96:373-381.

20. Kaifie A, Kirschner M, Wolf D, et al. Bleeding, thrombosis, and anticoagulation in myeloproliferative neoplasms (MPN): analysis from the German SAL-MPN-registry. J Hematol Oncol 2016;9:18.

21. Vianello F, Cella G, Osto E, et al. Coronary microvascular dysfunction due to essential thrombocythemia and pol- icythemia vera: the missing piece in the puzzle of their increased cardiovascular risk? Am J Hematol 2015;90:109113.

22. Guadall A, Lesteven E, Letort G, et al. Endothelial cells harbouring the JAK2 V6 $17 \mathrm{~F}$ mutation display pro-adherent and pro-thrombotic features. Thromb Haemost 2018;118:1586-1599.

23. Guy A, Gourdou-Latyszenok V, Le Lay N, et al. Vascular endothelial cell expression of $\mathrm{JAK}_{2} \mathrm{~V}_{17} \mathrm{~F}$ is sufficient to promote a pro-thrombotic state due to increased P-selectin expression. Haematologica 2019;104:70-81.

24. Castiglione M, Jiang YP, Mazzeo C, et al. Endothelial JAK2V617F mutation leads to thrombosis, vasculopathy, and cardiomyopathy in a murine model of myeloproliferative neoplasm. J Thromb Haemost 2020;18:3359-3370.

25. Passamonti F, Thiele J, Girodon F, et al. A prognostic model to predict survival in 867 World Health Organization-defined essential thrombocythemia at diagnosis: a study by the International Working Group on Myelofibrosis Research and Treatment. Blood 2012;120:1197-1201.

26. Barbui T, Finazzi G, Carobbio A, et al. Development and validation of an International Prognostic Score of thrombosis in World Health Organization-essential thrombocythemia (IPSET-thrombosis). Blood 2012;120:5128-5133.

27. Haider M, Gangat N, Lasho T, et al. Validation of the revised international prognostic score of thrombosis for essential thrombocythemia (IPSET-thrombosis) in 585 mayo clinic patients. Am J Hematol 2016;91:390-394.

28. Barbui T, Thiele J, Ferrari A, Vannucchi AM, Tefferi A. The new WHO classification for essential thrombocythemia calls for revision of available evidences. Blood Cancer J 2020;10:22.

29. Finazzi G, Carobbio A, Thiele J, et al. Incidence and risk factors for bleeding in 1104 patients with essential thrombocythemia or prefibrotic myelofibrosis diagnosed according to the 2008 WHO criteria. Leukemia 2012;26:716719 . 
KJIM

The Korean Journal of Internal Medicine Vol. 36, No. 5, September 2021

Supplementary Table 1. Cox's regression analysis seeking risk factors for thrombosis in essential thrombocythemia $(\mathrm{n}=139)$

\begin{tabular}{|c|c|c|c|c|c|c|}
\hline \multirow{2}{*}{ Variable } & \multicolumn{3}{|c|}{ Univariate analysis } & \multicolumn{3}{|c|}{ Multivariate analysis } \\
\hline & HR & $95 \% \mathrm{CI}$ & $p$ value & HR & $95 \% \mathrm{CI}$ & $p$ value \\
\hline Age $>60$ years & 2.53 & $1.27-5.03$ & 0.008 & 1.73 & $0.83-3.62$ & 0.141 \\
\hline Male sex & 2.04 & $1.08-3.89$ & 0.029 & 1.53 & $0.73-3.22$ & 0.262 \\
\hline $\mathrm{WBC}>12.0 \times 10^{9} / \mathrm{L}$ & 1.27 & $0.66-2.44$ & 0.482 & - & - & - \\
\hline Platelet $>1,000 \times 10^{9} / \mathrm{L}$ & 0.98 & $0.52-1.84$ & 0.943 & - & - & - \\
\hline Positive $J A K_{2} \mathrm{~V}{ }_{17} \mathrm{~F}$ & 2.09 & $0.86-5.08$ & 0.104 & - & - & - \\
\hline Hypertension & 2.60 & $1.41-4.81$ & 0.002 & 1.92 & $0.99-3.74$ & 0.56 \\
\hline Diabetes mellitus & 0.88 & $0.34-2.23$ & 0.783 & - & - & - \\
\hline Chronic kidney disease & 3.25 & $1.73-6.12$ & 0.001 & 2.29 & $1.15-4.57$ & 0.018 \\
\hline Smoking & 2.59 & $1.36-4.94$ & 0.004 & 2.40 & $1.26-4.58$ & 0.008 \\
\hline
\end{tabular}

HR, hazard ratio; CI, confidence interval; WBC, white blood cell; JAK2, Janus kinase 2. 
Supplementary Table 2. Cox's regression analysis seeking for risk factors for thrombosis in prefibrotic/early primary myelofibrosis $(n=42)$

\begin{tabular}{|c|c|c|c|c|c|c|}
\hline \multirow{2}{*}{ Variable } & \multicolumn{3}{|c|}{ Univariate analysis } & \multicolumn{3}{|c|}{ Multivariate analysis } \\
\hline & HR & $95 \% \mathrm{CI}$ & $p$ value & $\mathrm{HR}$ & $95 \% \mathrm{CI}$ & $p$ value \\
\hline Age $>60$ years & $5 \cdot 54$ & $1.25-24.59$ & 0.024 & 2.43 & $0.40-14.66$ & 0.332 \\
\hline Male sex & 1.56 & $0.57-4.32$ & 0.389 & - & - & - \\
\hline $\mathrm{WBC}>12.0 \times 10^{9} / \mathrm{L}$ & 0.83 & $0.31-2.23$ & 0.709 & - & - & - \\
\hline $\mathrm{WBC}>20.0 \times 10^{9} / \mathrm{L}$ & 0.55 & $0.07-4.18$ & 0.565 & - & & \\
\hline Platelet > 1,000 × 109/L & 0.17 & $0.04-0.74$ & 0.018 & 0.22 & $0.05-0.99$ & 0.049 \\
\hline IPSS intermediate-1 & 4.68 & $1.61-23.57$ & 0.004 & 3.63 & $1.24-10.66$ & 0.019 \\
\hline Positive JAK2V617F & 0.85 & $0.31-4.22$ & 0.848 & - & - & - \\
\hline Hypertension & 0.99 & $0.61-1.62$ & 0.969 & - & - & - \\
\hline Diabetes mellitus & 0.90 & $0.51-1.59$ & 0.718 & - & - & - \\
\hline Chronic kidney disease & 0.95 & $0.54-1.67$ & 0.849 & - & - & - \\
\hline Smoking & 0.85 & $0.50-1.45$ & 0.550 & - & - & - \\
\hline
\end{tabular}

HR, hazard ratio; CI, confidence interval; WBC, white blood cell; IPSS, International Prognostic Scoring System; JAK2, Janus kinase 2. 
KJIM'

The Korean Journal of Internal Medicine Vol. 36, No. 5, September 2021

Supplementary Table 3. Cox's regression analysis seeking risk factors for thrombosis in polycythemia vera $(\mathbf{n}=124)$

\begin{tabular}{lccc}
\hline \multirow{2}{*}{ Variable } & \multicolumn{3}{c}{ Univariate analysis } \\
\cline { 2 - 4 } Age $>$ 60 years & HR & $95 \%$ CI & 0.183 \\
Male sex & 1.51 & $0.83-2.71$ & 0.489 \\
WBC $>12.0 \times 10^{9} / \mathrm{L}$ & 0.81 & $0.44-1.45$ & 0.914 \\
Platelet $>450 \times 10^{9} / \mathrm{L}$ & 1.04 & $0.50-2.16$ & 0.552 \\
Positive JAK2V617F & 0.80 & $0.39-1.66$ & 0.351 \\
Hypertension & 1.32 & $0.75-2.38$ & 0.583 \\
Diabetes mellitus & 0.92 & $0.69-1.23$ & 0.026 \\
Chronic kidney disease & 2.04 & $1.09-3.82$ & 0.784 \\
Smoking & 0.91 & $0.45-1.83$ & 0.428 \\
\hline
\end{tabular}

HR, hazard ratio; CI, confidence interval; WBC, white blood cell; JAK2, Janus kinase 2. 
Supplementary Table 4. Cox's regression analysis seeking risk factors for thrombosis occurring after diagnosis of myeloproliferative neoplasms $(\mathbf{n}=335)$

\begin{tabular}{|c|c|c|c|c|c|c|}
\hline \multirow{2}{*}{ Variable } & \multicolumn{3}{|c|}{ Univariate analysis } & \multicolumn{3}{|c|}{ Multivariate analysis } \\
\hline & HR & $95 \% \mathrm{CI}$ & $p$ value & HR & $95 \% \mathrm{CI}$ & $p$ value \\
\hline Age $>60$ years & 1.20 & $0.49-2.93$ & 0.697 & - & - & - \\
\hline Male sex & 1.65 & $0.65-4.15$ & 0.290 & - & - & - \\
\hline Palpable splenomegaly & 0.57 & $0.07-4.45$ & 0.595 & - & - & - \\
\hline $\mathrm{WBC}>12.0 \times 10^{9} / \mathrm{L}$ & 0.64 & $0.25-1.61$ & 0.344 & - & - & - \\
\hline Platelets $>1,000 \times 10^{9} / \mathrm{L}$ & 1.00 & $0.36-2.81$ & 0.996 & - & - & - \\
\hline $\mathrm{LDH}>1.5 \times \mathrm{UNL}$ & 1.49 & $0.56-3.96$ & 0.426 & - & - & - \\
\hline Positive for $J A K_{2} V_{617} F$ & 1.49 & $0.42-5.33$ & 0.545 & - & - & - \\
\hline Prior thrombosis & 1.61 & $0.63-4.14$ & 0.322 & - & - & - \\
\hline ET & 0.81 & $9.33-1.98$ & 0.639 & - & - & - \\
\hline Pre-PMF & 0.19 & $0.02-1.50$ & 0.116 & - & - & - \\
\hline PV & 2.31 & $0.96-5 \cdot 5^{2}$ & 0.061 & 2.16 & $0.90-5.19$ & 0.084 \\
\hline Hypertension & 1.43 & $0.60-3.40$ & 0.423 & - & - & - \\
\hline Diabetes mellitus & 0.92 & $0.30-2.81$ & 0.881 & - & - & - \\
\hline Chronic kidney disease & 2.68 & $1.12-6.43$ & 0.027 & 2.51 & $1.05-6.04$ & 0.040 \\
\hline Smoking & 1.32 & $0.52-3.34$ & 0.565 & - & - & - \\
\hline
\end{tabular}

HR, hazard ratio; CI, confidence interval; WBC, white blood cell; LDH, lactate dehydrogenase; UNL, upper normal limit; JAK2, Janus kinase 2; ET, essential thrombocythemia; pre-PMF, prefibrotic/early primary myelofibrosis; PV, polycythemia vera. 
Supplementary Table 5. Cox's regression analysis seeking risk factors for thrombosis occurring after diagnosis of essential thrombocythemia $(n=139)$

\begin{tabular}{|c|c|c|c|c|c|c|}
\hline \multirow{2}{*}{ Variable } & \multicolumn{3}{|c|}{ Univariate analysis } & \multicolumn{3}{|c|}{ Multivariate analysis } \\
\hline & $\mathrm{HR}$ & $95 \% \mathrm{CI}$ & $p$ value & $\mathrm{HR}$ & $95 \% \mathrm{CI}$ & $p$ value \\
\hline Age $>60$ years & 0.44 & $0.08-2.34$ & 0.334 & - & - & - \\
\hline Male sex & 0.73 & $0.16-3.38$ & 0.685 & - & - & - \\
\hline $\mathrm{WBC}>12.0 \times 10^{9} / \mathrm{L}$ & 0.44 & $0.05-3.82$ & 0.460 & - & - & - \\
\hline Platelet $>1,000 \times 10^{9} / \mathrm{L}$ & 0.30 & $0.04-2.58$ & 0.274 & - & - & - \\
\hline Positive JAK2V6 $17 \mathrm{~F}$ & 1.90 & $0.20-17.57$ & 0.574 & - & - & - \\
\hline Prior thrombosis & 2.79 & $0.59-13.18$ & 0.196 & - & - & - \\
\hline Hypertension & 4.83 & $0.92-25.90$ & 0.066 & 2.73 & $0.44-16.80$ & 0.278 \\
\hline Diabetes mellitus & 1.06 & $0.12-9.29$ & 0.961 & - & - & - \\
\hline Chronic kidney disease & 9.02 & $1.86-43.84$ & 0.006 & 9.02 & $1.86-43.84$ & 0.006 \\
\hline Smoking & 0.79 & $0.09-6.88$ & 0.831 & - & - & - \\
\hline
\end{tabular}

HR, hazard ratio; CI, confidence interval; WBC, white blood cell; JAK2, Janus kinase 2. 
Supplementary Table 6. Cox's regression analysis seeking risk factors for hemorrhage in myeloproliferative neoplasm $(\mathbf{n}=335)$

\begin{tabular}{|c|c|c|c|}
\hline \multirow{2}{*}{ Variable } & \multicolumn{3}{|c|}{ Univariate analysis } \\
\hline & HR & $95 \% \mathrm{CI}$ & $p$ value \\
\hline Age $>60$ years & 1.26 & $0.54-2.76$ & 0.625 \\
\hline Male sex & $3 \cdot 57$ & $1.32-9.68$ & 0.012 \\
\hline Palpable splenomegaly & 0.46 & $0.06-3.50$ & 0.450 \\
\hline $\mathrm{WBC}>12.0 \times 10^{9} / \mathrm{L}$ & 0.69 & $0.32-1.51$ & 0.351 \\
\hline Platelet $>1,000 \times 10^{9} / \mathrm{L}$ & 1.24 & $0.50-2.04$ & 0.646 \\
\hline $\mathrm{LDH}>1.5 \times \mathrm{UNL}$ & 1.01 & $0.39-2.60$ & 0.983 \\
\hline Positive $J A K_{2} \mathrm{~V}_{17} \mathrm{~F}$ & 1.71 & $0.48-6.08$ & 0.404 \\
\hline ET & 0.69 & $0.30-1.57$ & 0.372 \\
\hline Pre-PMF & 1.27 & $0.42-3.87$ & 0.676 \\
\hline PV & 1.65 & $0.75-3.63$ & 0.215 \\
\hline $\mathrm{PMF}$ & 0.37 & $0.05-2.83$ & 0.338 \\
\hline Cytoreductive therapy & 0.95 & $0.39-2.34$ & 0.915 \\
\hline Hypertension & 1.09 & $0.49-2.39$ & 0.838 \\
\hline Diabetes mellitus & 0.70 & $0.24-2.11$ & 0.531 \\
\hline Chronic kidney disease & 0.96 & $0.35^{-2.64}$ & 0.936 \\
\hline Smoking & 2.03 & $0.90-4.56$ & 0.087 \\
\hline
\end{tabular}

HR, hazard ratio; CI, confidence interval; WBC, white blood cell; LDH, lactate dehydrogenase; UNL, upper normal limit; JAK2, Janus kinase 2; ET, essential thrombocythemia; pre-PMF, prefibrotic/early primary myelofibrosis; PV, polycythemia vera; PMF, primary myelofibrosis. 


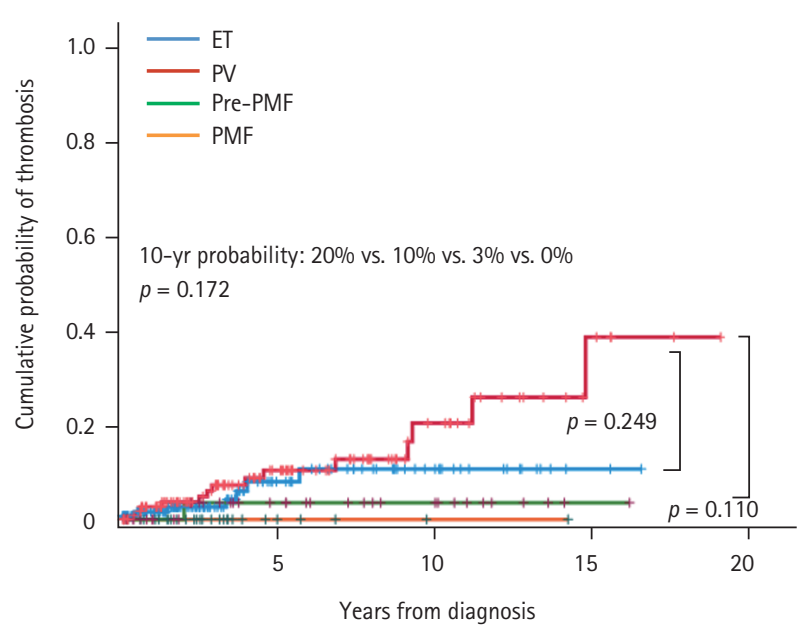

Supplementary Figure 1. Cumulative probabilities of thrombosis developing after diagnosis in patients with the various myeloproliferative neoplasm subtypes. ET, essential thrombocythemia; PV, polycythemia vera; pre-PMF, prefibrotic/ early primary myelofibrosis; PMF, primary myelofibrosis. 
A

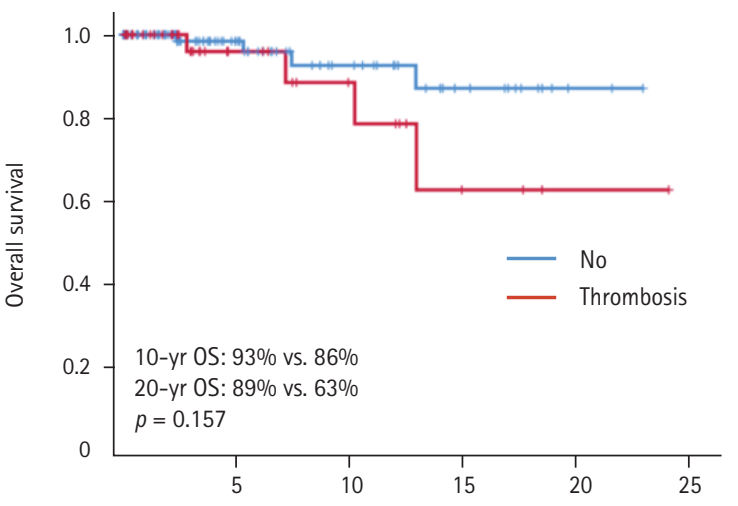

Years from diagnosis

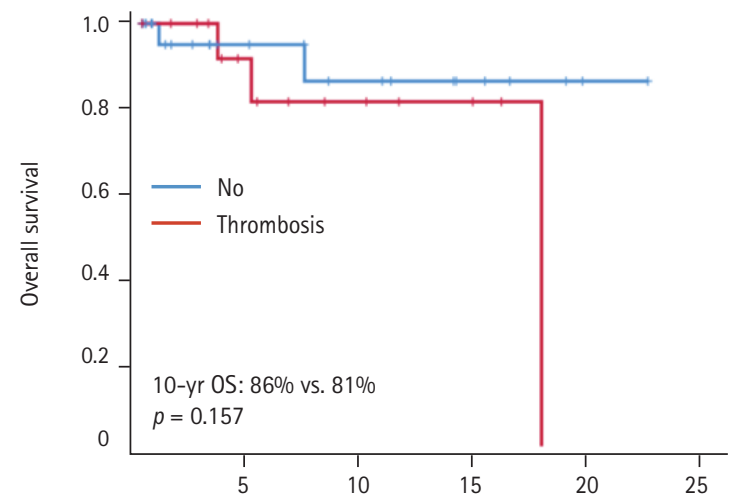

C

Years from diagnosis

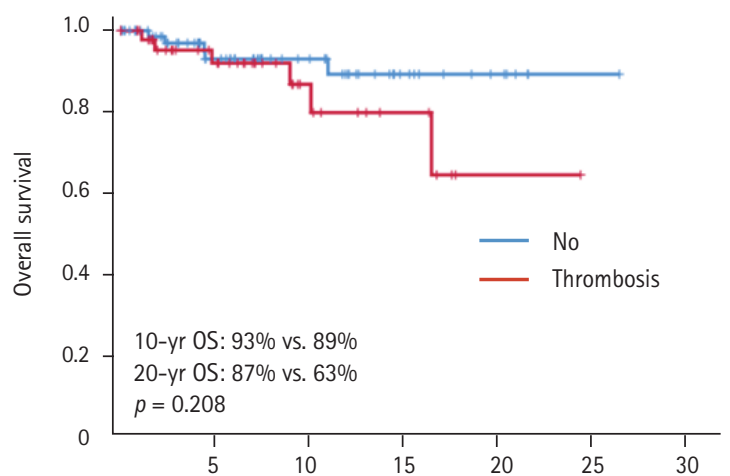

B

Years from diagnosis

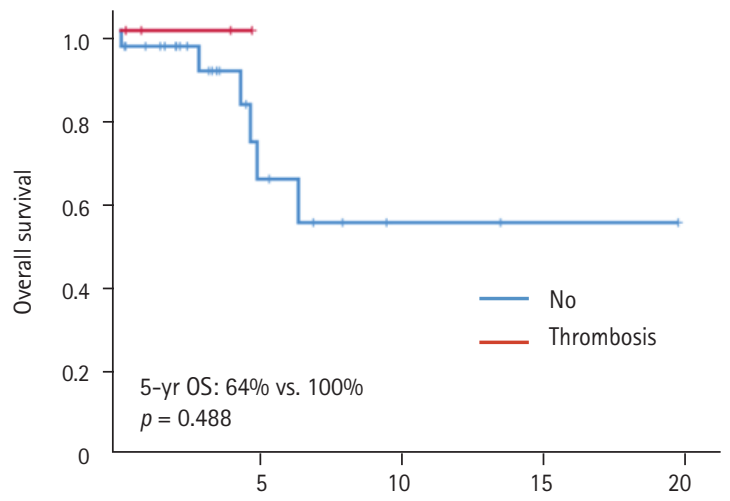

D

Years from diagnosis

Supplementary Figure 2. Overall survival (OS) of patients with myeloproliferative neoplasms with and without thromboses. (A) Essential thrombocythemia patients. (B) Polycythemia vera patients. (C) Prefibrotic/early primary myelofibrosis patients. (D) Primary myelofibrosis patients. 